原 著

\title{
脳出血と脳梗塞の同一患者での発生
}

\author{
山下 晃平, ${ }^{* 1}$ 柴田 家門, ${ }^{* 1}$ 清 木 義 勝, ${ }^{* 1}$ 小林 豊*1 \\ 西川秀人, ${ }^{* 1}$ 寺尾 栄夫, ${ }^{* 1}$ 長谷川 元治, ${ }^{* 2}$ 御 任 明 利*3 \\ 串田良昌, ${ }^{* 4}$ 小名木 敦雄*4
}

\section{Rare Occurrence of Intracerebral Hemorrhage and Infarction in Same Patientes}

Kouhei Yamashita, M.D., ${ }^{* 1}$ Iekado Shibata, M.D., ${ }^{* 1}$ Yoshikatsu Seiki, M.D.,1

Yutaka Kobayashi, M.D., ${ }^{* 1}$ Hideto Nishikawa, M.D., ${ }^{* 1}$ Hideo Terao, M,D.,

Motoharu Hasegawa, M.D., ${ }^{* 2}$ Toshiaki Mro, M.D.," Yoshimasa Kushida, M.D., ${ }^{* 4}$ and Atsuo ONAGI, M.D. ${ }^{* 4}$

Departments of ${ }^{* 1}$ Neurosurgery and ${ }^{* 2}$ Clinical Functional Physiology, Toho University

School of Medicine, Tokyo, ${ }^{* 3}$ Department of Neurosurgery, Sagamihara

Central Hospital, Sagamihara, and ${ }^{* 4}$ Department of Neurosurgery,

Saiseikai Yokohama Southern Area Hospital, Yokohama, Japan

Summary : Occurrence of cerebral hemorrhage and infarction in the same patient at various intervals seems to be rather rare. Among 962 cases of cerebrovascular diseases in our university hospital during a recent seven year peried, incuding 314 cerebral hemorrhage and 300 cerebral infarction, recurrent intracerebral hemorrhage and recurrent cerebral infarction occurred in 11 cases $(1.2 \%)$ and 124 cases $(12.9 \%)$ respectively. On the other hand, cerebral hemorrhage ana infarction in the same patient was encountered in only five cases.

Retrospective analysis of clinical data, including blood pressure, site of lesion, systemic disease, grade of arteriosclerosis, was attempted in order to make clear the underlying pathophysiology in these cases.

Additionally, arteriosclerosis of the carotid and vertebral artery was estimated as a wall Stiffness Parameter $(\beta$ value) by Ultrasonic Phase-locked Echo Tracking System.

The mean age of the five patients was 64.5 , which was higher than the reccurent hemorrhage group and the reccurent infarction group. All patients were male. Intracerebral hemorrhage and in farction occurred on the same side in all cases. Howerver, hemorrhage and infarction did not occur in the same arterial territory; for instance, hemorrhage occurred in the anterior cerebral artery area and infarction occurred in the middle cerebral artery area. The time interval between the two cerebrovascular incidents was one month to seven years. Systemic hypertention was present in all cases and diabetes mellitus accompanied three cases. None of the cases had hyperlipemia.

In our extensive study on the Stiffiness Parameter of carotid and vertebral arteries so far, the $\beta$ value increases proportionally to the patient's age in the infarction group, as well as in the diabetic group. On the other hand, the $\beta$ value in the hypertensive group was variable and definite correlation between the $\beta$ value and the patient's age was not established. The $\beta$ value measured in a case with hemorrhage and infarction was obviously high. Intracerebral hemorrhage and infarction had a
Key words :

- intracerebral hemorrhage

- cerebral hemorrhage

- same patients

- arteriosclerosis

- Ultrasonic Phase-locked Echo Tracking System

${ }^{* 1}$ 東邦大学 脳神経外科, ${ }^{* 2}$ 同 臨床生理機能科, ${ }^{* 3}$ 相模原中央病院 脳神経外科, ${ }^{* 4}$ 済生会横浜南部病院 脳神経外科 
different pathophysiological basis for their occurrence; principal pathological change in hypertensive intracerebral hemorrhage is believed to be a development of microaneurysm and fiblinoid degeneration of the artery wall. On the other hand, cerebral infarction is belived to occur as the result of arteriosclerotic narrowing of the artery. This can explain the rare occurrence of intracerebral hemorrhage and infarction in the same patient and the fact that hemorrhage and infarction developed in different arterial territories. Frequent measurements of $\beta$ value of the carotid and vertebral artery may predict the occurrence of cerebral infarction, even in a patient with cerebral hemorrhage.

\section{はじめに}

本邦の脳血管障害のうち，脳出血は約20３0\%で，脳梗 塞はその約 1.5 倍と報告されている。，そのうち出血性梗塞 を除外した出血および梗塞の合併例は，脳出血または脳梗 塞単独の再発例と比較し，きわめてまれである.

今回われわれは，時期を異にして発症した脳出血と脳梗 塞の合併例 5 例について, 年齢, 性別, 発生部位, 基礎疾 患などの諸因子との関連性を検討した。 さらに，病態生理 については，超音波変位法を用いて，脳の動脈硬化度の面 より検討したので，若干の文献的考察を加えて報告する.

\section{対象および方法}

昭和 55 年 1 月より昭和 61 年 11 月までの 6 年 11 かに，東 邦大学脳神経外科ならびに関連施設において入院治療を行 った脳血管障害の総患者数は962例であり，そのうち脳出

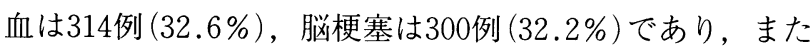
脳出血症例の再発例は11例 $(1.2 \%)$, 脳梗塞症例の再発例 は124例 (12.9\%)であった。ところで，同一症例で脳出血 と脳梗塞を時期を異にして合併した症例は予想外に少なく 5 症例のみであったが，今回この 5 症例につき検討を加え た.

また，われわれの行っている超音波変位法到については 多少の説明を要すると思われるので，簡単に述べることに する．これは位相追跡システムを内蔵したリニヤスキャン

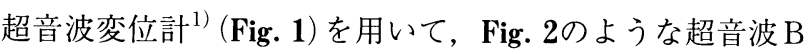
モード像を求め, 左右の総頸動脈, 頸動脈洞, 内頸動脈, 椎骨動脈の口径変位分 $(\Delta \mathrm{D})$, 最小血圧時口径 $(\mathrm{Dd})$ を測定 し, さらに最大・最小血圧值から、 $\beta=($ In $\mathrm{Ps} / \mathrm{Pd})$ ・ $\mathrm{Dd} / \Delta \mathrm{D}$ (Fig. 3)の式により Stiffness Parameter $\beta$ を求め, その值の高低により動脈硬化度を判定する方法である ${ }^{2) 31}$ 4).

対象とした正常群は，0歳〜 70歳台の1307例，糖尿病群 は30歳台〜70歳台の99例，そして脳梗塞群は，30歳台～70 歳台の100例である．また，脳出血例は今までに約 60 例を 測定した. 脳出血と脳梗塞の合併例 5 例については, Case 2についてのみ本検査を行った.

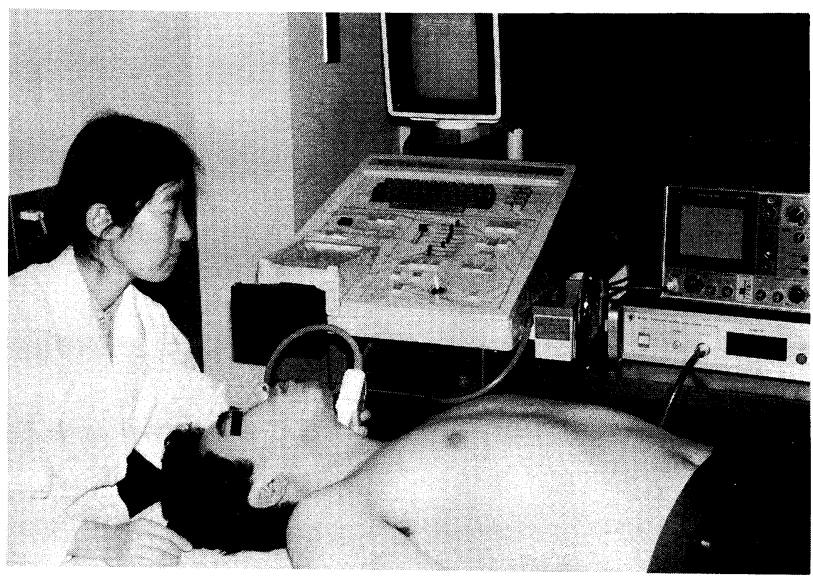

Fig. 1 Examination by the Ultrasonic Phase-locked Echo Tracking System.

\section{結果}

\section{1. 症例 (Table 1)}

\section{(1)性別・年龄}

性別は 5 症例全例が男性であり，年齢は55歳から82歳ま での平均 64.8 歳で，脳出血の平均年齢 55.4 歳掞よび脳梗 塞の平均年齢 59.7 歳に比べ高齢であった。

\section{(2)CT における発生部位}

$\mathrm{CT}$ 上の発生部位をみると，5症例すべて出血と梗塞は 同側半球にみられた。また出血部位は，視床が 5 例中 3 例 と最も多く. 被殼・小脳は各 1 例であった。梗塞部位は, 前大脳動脈領域 1 例, 中大脳動脈領域 2 例, 深部穿通枝領 域 2 例とさまざまであった。

\section{(3)基礎疾患}

高血圧症は，5例全例に認められた。また 5 例中 3 例に 糖尿病と心疾患を合併していた。なお、血液検査では，高 脂血症は 1 例も認められなかった，以下に，代表的な 3 症 例を提示する.

\section{〈症例 3 〉65歳男性.}

昭和57年 3 月, 構語障害と左片麻痺が出現し, CT scan において右側頭葉から被殼にかけて, low density area が 認められ，脳梗塞の診断のもとに保存的に治療を行ったが、 3 年後の昭和 60 年 1 月にCT scan 上, 脳室穿破を伴う右 視床出血を合併した (Fig. 4). 


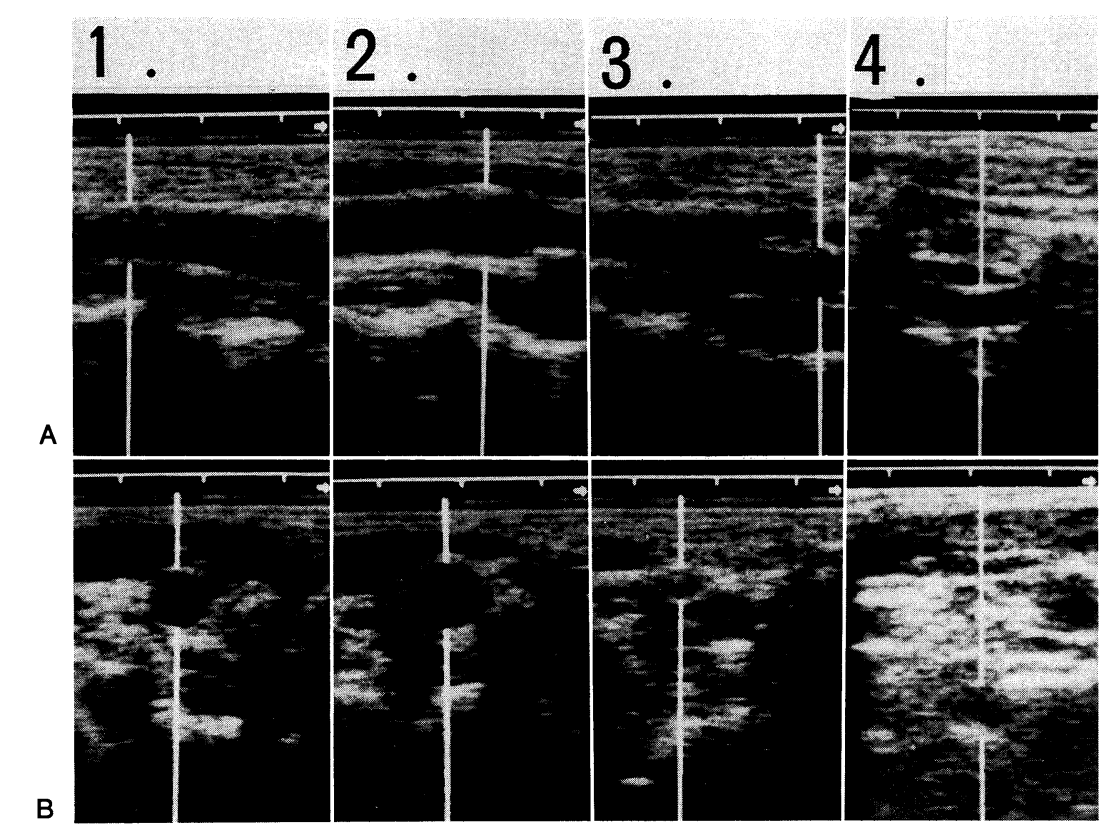

Fig. 2 Echograms of arteries. A: A longitudinal section, B: A cross section, 1: Common carotid artery, 2: Carotid sinus, 3: Internal carotid artery, 4: Vertebral artery.

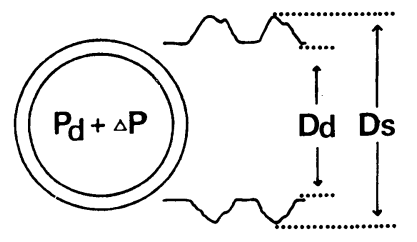

\section{$P_{S}$ : Systolic Pressure \\ Diameter ..... Ds \\ Pd: Diastolic Pressure \\ Diameter.... Dd \\ $P_{S}=P_{d}+\Delta P$}

\section{Stiffness Parameter $(\beta$ ) \\ $\beta=\left(\ln \mathbf{P}_{\mathbf{S}} / \mathbf{P}_{\mathbf{d}}\right) \cdot \mathrm{Dd} /(\mathbf{D s}-\mathrm{Dd})$ \\ $=\left(\ln P_{S} / P_{d}\right) \cdot D d / \Delta D$}

Fig. 3 Formula for caliculation of the Stiffness Parameter $\langle\beta\rangle$.

\section{〈症例 4〉82歳男性.}

昭和 58 年 9 月に歩行障害, 左不全麻痺にて発症し, CT scan にて右被款に low density area を認め, 脳梗塞と診 断され保存的に治療され症状は軽快した.しかし、2 年後 の昭和60年 9 月, 小脳出血を合併しその数日後に脳へルニ アにて死亡した (Fig. 5).

\section{〈症例 5〉60歳男性.}

昭和57年, 他院にて左被殼出血を伴った右中大脳動脈瘤 破裂に対して clipping 術を施行されたが，2 年後の昭和 59年に, 右半身の不全麻痺・言語障害が出現し, CT scan にて左被款の梗塞および脳室穿破を伴う右視床出血が認め られた(Fig. 6).

\section{Stiffness Parameter $(\beta)$ の分布}

超音波変位法により, 健常群, 糖尿病群, 脳梗塞群の Stiffness Parameter $(\beta)$ の分布を求め表にした (Fig. 7).

健常群についてみてみると, 加齢により, Stiffness Pa$\operatorname{rameter}(\beta)$ の值は大きくなる.すなわち加齢により動脈硬 化が進むことを表わしている5).さらに糖尿病群および脳 梗塞群では, いずれも parameter $(\beta)$ は, 30代から70代の 各年代において, 健常群に比べて明らかに高値を示し, 非 常に類似した曲線の形をとっており, 数值的にも近い值と なっている. しかし, 脳出血群においては同年代における $\beta$ 值にばらつきが多く, きれいなグラフが描けないことに より, 必ずしも頸部での動脈硬化度と脳出血の発症とは相 関しない傾向にあった. 脳出血と脳梗塞合併例の para$\operatorname{meter}(\beta)$ の值は15と明らかに高值を示した。

\section{考察}

脳出血の成因として, 細血管説 ${ }^{6)}$, 静脈説 ${ }^{7)}$, 動脈硬化 説 $^{8)}$, 血漿壊死説 ${ }^{9)}$ などが報告されているが, 現在, 血漿 性動脈壊死に基づく微小動脈瘤破綻説が最も有力である ${ }^{9)}$. 一方, 脳梗塞は血管壁のアテローム変化による動脈硬化と, それにより 2 次的に作られた血栓，もしくは心疾患により 形成された血栓の遊離による塞栓が, 大部分の原因を占め ている.

先に提示した 5 症例は, 出血と梗塞という全く異なる病 態が, 同一症例で発生したとしか考えられず、その発生率 は脳梗塞のみの再発率や脳出血のみの再発率に比べ当然の 
Table 1 Clinical summary of five cases

\begin{tabular}{|c|c|c|c|c|}
\hline Case & $\begin{array}{l}\text { Age/ } \\
\text { Sex }\end{array}$ & $\begin{array}{c}\text { First and } \\
\text { second attack }\end{array}$ & $\begin{array}{l}\text { CT findings } \\
\text { (location) }\end{array}$ & $\begin{array}{l}\text { Complicated } \\
\text { disease }\end{array}$ \\
\hline 1 & $55 / \mathrm{M}$ & $\begin{array}{l}\text { infarction } \\
\rightarrow \text { hemorrhage } \\
1 \text { month }\end{array}$ & $\begin{array}{l}\text { Inf. } \rightarrow \text { rt-frontal } \\
\text { Hemo. } \rightarrow \text { rt-thalamus }\end{array}$ & H.T. \\
\hline 2 & $62 / \mathrm{M}$ & $\begin{array}{l}\text { hemorrhage } \\
\rightarrow \text { infarction } \\
7 \text { years }\end{array}$ & $\begin{array}{l}\text { Hemo. } \rightarrow \text { rt-thalamus (I.V.H. } \oplus \text { ) } \\
\text { Inf. } \quad \rightarrow \text { rt-occipital-temporal }\end{array}$ & $\begin{array}{l}\text { H.T. } \\
\text { D.M. } \\
\text { I.H.D., A.f. }\end{array}$ \\
\hline 3 & $65 / \mathrm{M}$ & $\begin{array}{l}\text { infarction } \\
\quad \rightarrow \text { hemorrhage } \\
3 \text { years }\end{array}$ & $\begin{array}{l}\text { Inf. } \rightarrow \text { rt-temporal } \sim \text { putamen } \\
\text { Hemo. } \rightarrow \text { rt-thalamus }(\text { I.V.H. } \oplus)\end{array}$ & $\begin{array}{l}\text { H.T. } \\
\text { D.M. } \\
\text { A.f. }\end{array}$ \\
\hline 4 & $82 / \mathrm{M}$ & $\begin{array}{l}\text { infarction } \\
\quad \rightarrow \text { hemorrhage } \\
2 \text { years }\end{array}$ & $\begin{array}{l}\text { Inf. } \rightarrow \text { rt-putamen } \\
\text { Hemo. } \rightarrow \text { cerebellum }\end{array}$ & $\begin{array}{l}\text { H.T. } \\
\text { Gout }\end{array}$ \\
\hline 5 & $60 / \mathrm{M}$ & $\begin{array}{c}\text { rt-MCA aneurysm } \\
\downarrow \\
\text { hemorrhage } \\
\downarrow \\
\text { hemorrhage, infarction }\end{array}$ & $\begin{array}{l}\text { Hemo. } \rightarrow \text { lt-putamen,rt-thalamus } \\
\quad(1 \mathrm{st}) \quad(2 \mathrm{nd}) \\
\text { Inf. } \quad \rightarrow \text { lt-putamen } \sim \text { temporal }\end{array}$ & $\begin{array}{l}\text { H.T. } \\
\text { D.M. } \\
\text { T.b. } \\
\text { Hepatitis } \\
\text { I.H.D. }\end{array}$ \\
\hline
\end{tabular}

I.V.H.: intra ventricular hemorrhage, H.T. Hypertension,

I.H.D.: Ischemic heart disease, A.f.: Atrial fibrillation.

A
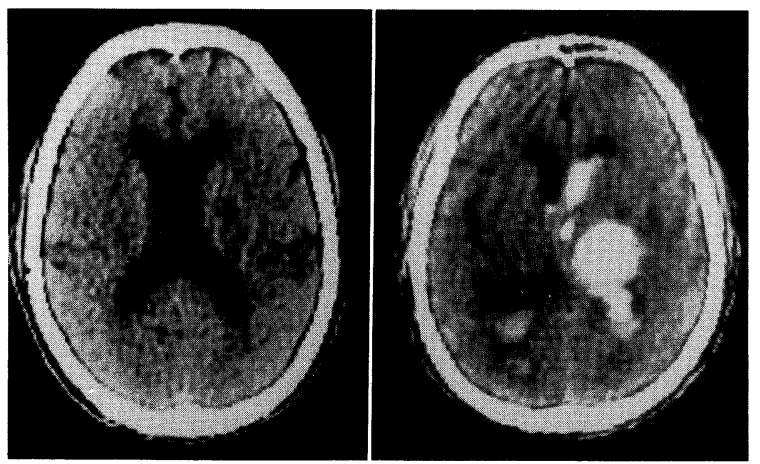

Fig. 4 Case 3. A: CT scan at the vascular first attack showing cerebral infarction in the right temporal putamen. B: CT scan at the second attack, showing a rt. putaminal hemorrhage with perforation into the ventricle.

ことながら低いものと考えられる，さらに，本 5 症例の検 討より, 脳出血と動脈硬化は, 同一の血管支配領域には発 症しにくいのではないかと推察される.すなわち, これら 5 症例の CT scan 上の発生部位を検討してみると, 小脳 出血例を除く, 出血と梗塞はすべて同側半球に発生しては いるものの, 初回梗塞で発症した 3 例 (Case 1, Case 3, Case 4)では, 出血は大脳半球の全く異なった動脈支配領 域や小脳に発生していることより, 通常考えられているよ うな, 梗塞により生じた脳軟化巣の血管壊死部からの出血 とは考えにくいと思われる. また, 初回出血で発症した 2 症例においても, 合併した梗塞部位は, 血管支配面から考 336 脳卒中の外科 $16: 1988$
A
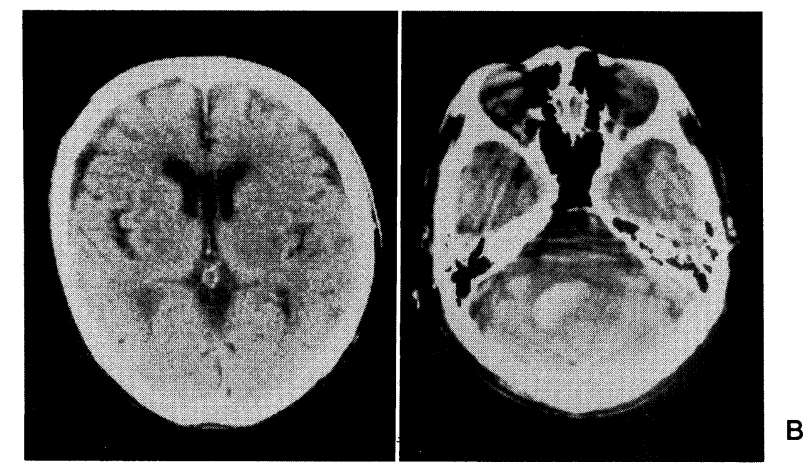

Fig. 5 Case 4. A: CT scan at the first cerebrovascular accident showing a cerebral infarction in the right putamen. B: CT scan at the second vascular attack showing cerebellar hemorrhage.

えても両者に直接的な因果関係は見い出されなかった。し かし Case 5については, 初回出血部位近くに合併梗塞巣 が認められ, かつ対側の右視床出血は, 多発性梗塞のうち の 1 ヶ所に出血性梗塞が起こったという考え方も否定でき ないであろう。しかし, 出血性梗塞は漏出性の出血であり,

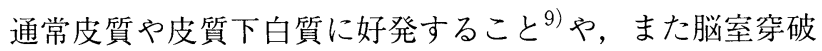
している出血の形からも, 破綻性の高血圧性出血と考えた ほうが妥当であると思われる.

一方, この 5 症例の基礎疾患に着目すると, 降圧剤によ りコントロールはされていたが, 全例に高血圧症があった。 しかし高血圧症の有無に関しては, 単独の梗塞または出血

336 脺中の外科 $16: 1988$ 
A
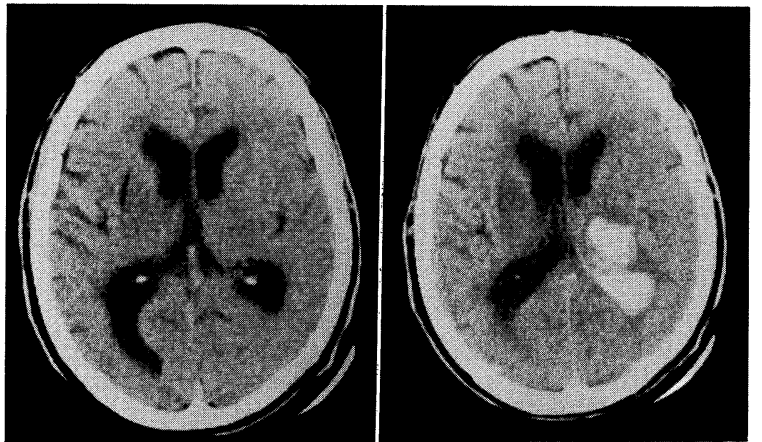

Fig. 6 Case 5. A: CT scan at the first attack showing a narrow, well demarcated low density area in left putamen. B: CT scan at the second vascular attack showing left putaminal infarction and right thalamic hemorrhage with ventricular perforation.

再発例についても同様な傾向を示していた。一方，このこ とは同じ条件下においては再梗塞例が再出血例に比べ明ら かに多いことを考えると，血圧のコントロール自体が，特 定の脳梗塞群にとっては一面において必ずしもよい影響を 与えていないのかもしれない.すなわち, 脳動脈は他の動 脈に比較して, 内腔の大きさに対し中膜が薄く ${ }^{9)}$,

Frank-Laplace $の$ 式,

$[($ 張力 $)=($ 内圧 $) \times($ 半径 $) /($ 壁圧 $)]$ からも分かるように, 血圧を下げれば，当然のことながら張力は低下し，血管の 破綻する確率は低下し, 出血の起こる可能性は減少すると 考えられるが，しかし加齢により動脈硬化の進行した例で は，逆に血圧の低下により血管の相対的狭窄を生じるので はないかとも考えられるからである，また，高血圧と同様 に頻度の高い基礎疾患である糖尿病について検討してみる とFig. 7 のグラフからもわかるように, 糖尿病群は同年代 の健常群より高い動脈硬化度を示している. 実際に脳梗塞 を起こした症例の年代別動脈硬化度や曲線の形も糖尿病群 に非常に類似していることから，糖尿病は脳動脈硬化の基 礎的因子，すなわち脳梗塞の risk factor に十分なりうる ものと考えられる. 動脈の形状と機能を noninvasive にと らえる超音波変位法により, 総頸動脈硬化の程度から脳動 脈硬化を予測することの妥当性は, すでに川崎, 荒井らが 報告 ${ }^{2)}$ ５) している. しかし、脳出血に関しては，先に述 ベたごとく同年代における $\beta$ 值がまちまちであり，必ず しも検査上は脳動脈硬化度とは相関していないようである。 Baker $^{10)}$ やStochdorph ${ }^{11)} ら も$ 報告しているように, 脳出 血は (1)内腔の大きさに比べ壁が薄い, (2)中膜は平滑筋細 胞が少なく薄い, (3)外弾性板を欠く, (4)外膜や周囲結合組 織の発達が貧弱, などの先天的な血管壁性因子が加わり発 症すると考えたほうがよいであろう. すなわち, 高血圧症 患者に脳出血を合併する頻度は高いが, すべての患者に発

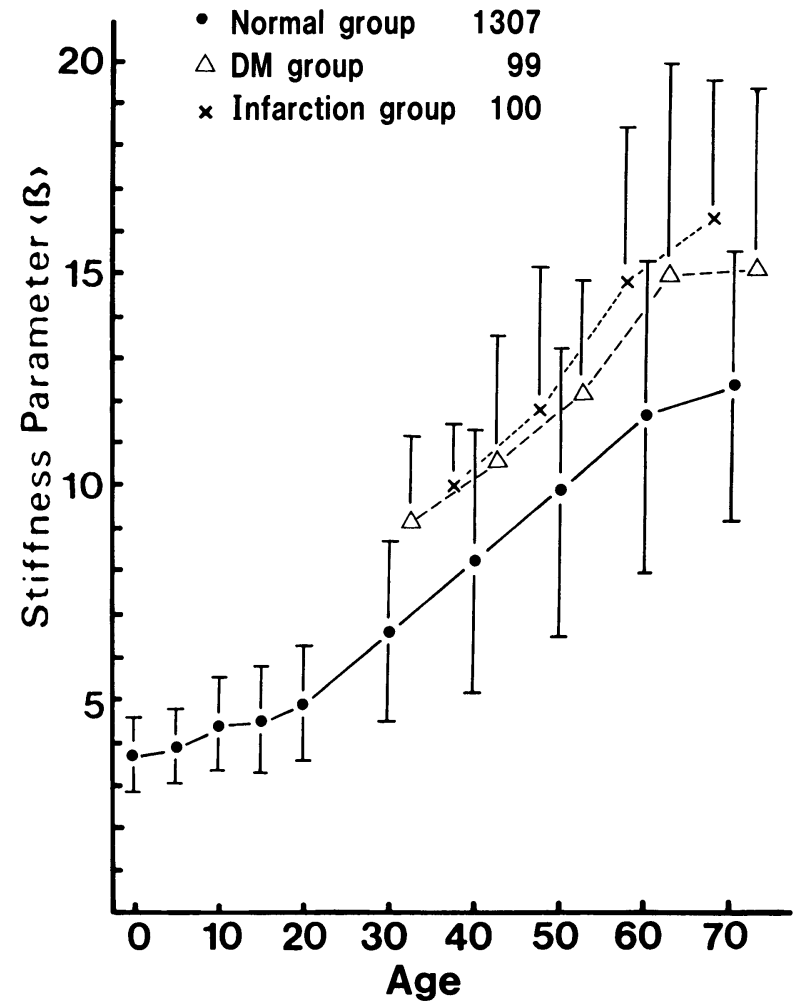

Fig. 7 Corelation of Stiffness parameter $\langle\beta\rangle$ and patient's age in infarction group and diabetic group.

症するわけではなく, 特定のものにのみ発症するのは, こ のような血管壁の先天的な特徵の個体差に基づく2次的な 血管壁の脆弱性部位の発生によるものと推察されるからで ある.しかし，脳梗塞に関しては以上の結果からも，全身 的な動脈硬化性因子に起因するものと考えられる.

\section{結語}

1.同一患者で時期を異にして発症した脳出血と脳梗塞 合併症例 5 例について, 年齢・性別・発生部位・基礎疾患 などの諸因子との関連性を検討し，さらに超音波変位法を 用いて病態生理の面からこれらを考察した。

2. 脳出血および脳梗塞合併症例の基礎的疾患として, 高血圧や糖尿病は重要な risk factor となりうるが, 高脂 血症に関してはあまり相関関係は認められなかった。

3. 脳出血および脳梗塞合併症例では, 全身的な血管因 子と先天的な血管因子の両方を共有しているといえる.

4. 超音波変位法は, 脳梗塞を予測する一手段として有効 である。

\section{文献}

1）木下重博，八木晋一：超音波変位計による頸動脈弾性特性 の測定. 医用電子と生体工学 13 (特別号): 409-410, 1975

2）川崎 健, 八木晋一, 長谷川元治, ほか：総頸動脈, 頸動 脈洞硬化判定に関する研究一超音波変位計を用いた多点計 
測による Stiffenss Parameter $\beta$ 分布について．動脈硬化 8 : 383-388, 1980

3）川崎 健，八木晋一，高山吉隆，ほか：超音波変位計によ る非観血的総頸動脈硬化判定法. 脈管学 22: 241-248, 1982

4）川崎 健，八木晋一，長谷川元治，ほか：超音波変位計に よる総頸動脈管軸方向 Stiffenss Parameter $\beta$ 分布の計測健常群, 脳梗塞群の対比一. 日本老人医学会雑誌 19 : 588-595, 1982

5）荒井親雄, 安部信行, 長谷川元治, ほか：Stiffenss Parameter $\beta$ 分布によるヒト頸動脈洞硬化の診断. 脈管学 $\mathbf{2 5}$ : 1199-1204, 1985

6) Roseblath: Über die Entstehung der Hirnblutung bei dem Schlaganfall. Dtsch Zscher Nervenheilk 61: 10-143, 1918

7) Scheinker IM: Changes in cerebral veins in hypertensive brain disease and their relation to cerebral hemorrhage. Ciinical pathologic study. Arch Neurol Psychiatry 54: 395-408, 1945

8) Zimmerman HM: Cerebral apoplexy, Mechanism and differential diagnosis. NY State J Med 49: 2153-2157, 1949

9) 大根田玄寿：脳出血の病理, 文光堂, 東京, $1974, \mathrm{pp}$ 20-114

10) Baker AB: Structure of the small cerebral arteries and their changes with age. Am J Path 13: 453-461, 1937

11) Stochdorph $\mathrm{O}$, Meessen $\mathrm{H}$ : Die arteriosklerotische und die hypertonische Hirnerkrankung in Handbuch der speziellen pathologischen Anatomie und Histologie, Springer-Verlag, Berlin, 1957, 13 (IB), pp 1465-1510 